\title{
Rh single atom catalyst for direct conversion of methane to oxygenates
}

\author{
Jian Lin and Xiaodong Wang*
}

Along with the fast development of economy and growth of world's population, the demand for energy is significantly enhanced. The conventional petroleum and coal resources are unrenewable and bring about severe pollution to the environment. In the past decade, the technological advances in drilling and exploitation lead to a significant increase in the production capacity of shale gas worldwide. The U.S. Energy Information Administration projects that the annual shale gas output would rise by $104 \%$ from 2012 to 2040, which could ignite "shale gas revolution" and change the energy landscape [1]. As we know, the main component in natural and shale gas is methane which contributes to $83 \%-99 \%$. Consequently, technologies utilizing methane efficiently are more and more recognized and predicted as leading actor in the coming century of natural/shale gas chemical engineering.

Up to now, the industrial approach of catalytic valorization of $\mathrm{CH}_{4}$ mainly comes through the routes of steam reforming to syngas, which can then be converted into methanol and other value added chemicals by FischerTropsch synthesis at a large scale [2]. Comparatively, the direct, one-step transformation of $\mathrm{CH}_{4}$ to liquid oxygenates, which is more energy-effective and economic for the avoidance of expensive syngas intermediates, has been proven difficult due to low conversion, selectivity and yield of target product. Particularly, the selective oxidation of methane to methanol, which is famous as a "holy grail" reaction in catalysis science, has long time been studied but bloomed again only recently. The scientific challenge lies in the inertness of methane molecules with low electron affinity and high $\mathrm{C}-\mathrm{H}$ bond energy of $439 \mathrm{~kJ} \mathrm{~mol}^{-1}$, causing the cleavage of first $\mathrm{C}-\mathrm{H}$ bond as the rate-determining step [3]. Various formulations of catalysts have been developed, particularly in mimic enzymatic systems of methane monooxygenases, among which the zeolites containing $\mathrm{Cu}$ or $\mathrm{Fe}$ species were reported as star catalysts to produce methanol from methane [4]. On these catalysts, the production of methanol originates from multi-steps of methane activation, conversion to methoxyl, then being extracted by $\mathrm{H}_{2} \mathrm{O}[5,6]$. These processes can lead to satisfactory selectivity of nearly $100 \%$, however, the rate of $\mathrm{CH}_{4}$ conversion and the yield of methanol are too low due to the stoichiometric production of methoxyl from the activation of methane on $\mathrm{Cu}$ or $\mathrm{Fe}$ sites in either stepwise or chemical looping modes.

The supported noble metal catalysts give another alternative but suffer from no serious consideration previously due to facile deep dissociation of $\mathrm{C}-\mathrm{H}$ bond and over-oxidation to $\mathrm{CO}_{2}$ on the metal sites. Nevertheless, the one-step conversion of $\mathrm{CH}_{4}$ to $\mathrm{CH}_{3} \mathrm{OH}$ or $\mathrm{CH}_{3} \mathrm{COOH}$ was feasible on homogeneous $\mathrm{Pt}$ or $\mathrm{Pd}$ based catalysts despite of using corrosive oxidants or media $[7,8]$. Moreover, the theoretical studies found that the metal sites with lower coordination number can stabilize $\mathrm{CH}_{3}$ species to avoid the successive dehydrogenation of $\mathrm{CH}_{4}$ [9]. Recently, corresponding author Prof. Maria FlytzaniStephanopoulos of Tufts University and her coworkers made a big breakthrough in the mild oxidation of methane not only to methanol but also to acetic acid by heterogeneous catalysis [10]. They prepared ZSM-5 supported Rh single atom catalyst by a simple wet chemistry method with $\mathrm{Rh}$ loading amount of around $0.5 \mathrm{wt} \%$. The typical image of high-angle annual dark-filed scanning transmission electron microscopy in Fig. 1a indicate that there are isolated Rh atoms on ZSM-5. The CO adsorption infrared spectroscopy result in Fig. $1 \mathrm{~b}$ further proves the presence of $\mathrm{Rh}$ single atoms from the peaks at 2,116 and $2,049^{-1} \mathrm{~cm}$ that are attributed to the symmetrical and asymmetrical stretching of $\mathrm{CO}$ from the isolated mononuclear $\mathrm{Rh}^{\mathrm{I}}(\mathrm{CO})_{2}$ species. Of great significance, this cat-

State Key Laboratory of Catalysis, Dalian Institute of Chemical Physics, Chinese Academy of Sciences, Dalian 116023, China

*Email: xdwang@dicp.ac.cn 


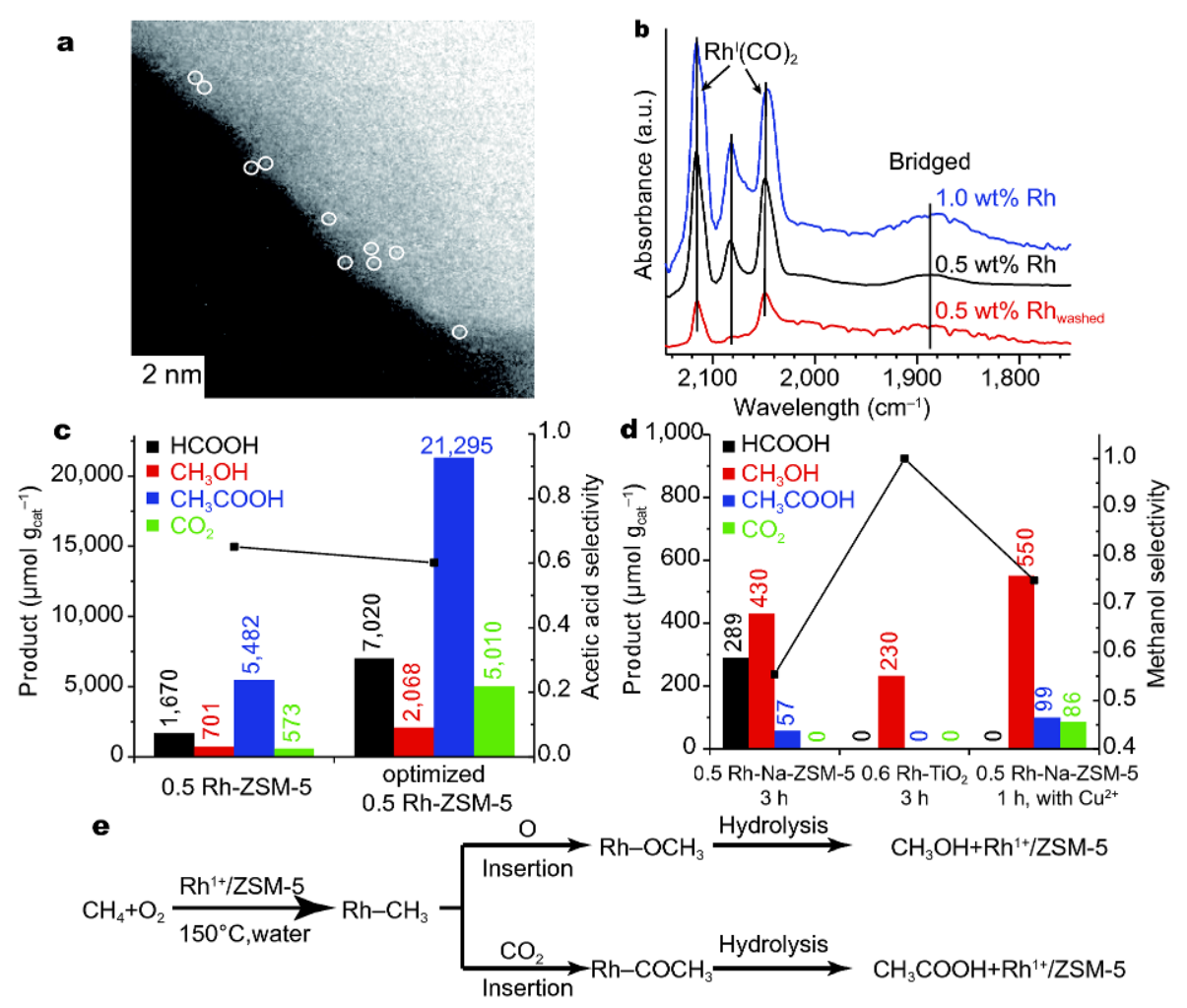

Figure 1 (a) Typical AC-HAADF-STEM images of $\mathrm{Rh}_{1} / \mathrm{ZSM}-5$ single-atom catalyst of which the isolated rhodium atoms are marked with white circles; (b) CO-DRIFTS spectra of $1.0 \mathrm{wt} \% \mathrm{Rh}-\mathrm{ZSM}-5,0.5 \mathrm{wt} \% \mathrm{Rh}-\mathrm{ZSM}-5$ and $0.5 \mathrm{wt} \% \mathrm{Rh}-\mathrm{ZSM}-5$ washed; (c) product yields and acetic acid selectivity for $0.5 \mathrm{wt} \% \mathrm{Rh}-\mathrm{ZSM}-5$ and optimized $0.5 \mathrm{wt} \% \mathrm{Rh}-\mathrm{ZSM}-5$ at 2 bar $\mathrm{O}_{2}$ and $3 \mathrm{~h}$ reaction time; (d) product yields and methanol selectivity for $0.5 \mathrm{wt} \% \mathrm{Rh}-\mathrm{Na}-\mathrm{ZSM}-5$ with and without $\mathrm{Cu}^{2+}$, as well as on $0.6 \mathrm{wt} \% \mathrm{Rh} / \mathrm{TiO}_{2}$, at 2 bar $\mathrm{O}_{2}$ and varying reaction time; (e) possible reaction pathways of the catalytic conversion of methane to methanol and acetic acid on Rh-ZSM-5. Reprinted with permission from Ref. [10], Copyright 2017, Nature Publishing Group.

alyst exhibited a good performance in the conversion of $\mathrm{CH}_{4}$ to $\mathrm{CH}_{3} \mathrm{COOH}$ with the presence of $\mathrm{CO}$ and $\mathrm{O}_{2}$ at mild conditions in batch-reactor conducted at $150^{\circ} \mathrm{C}$. On the optimized catalyst of Rh-ZSM-5 with all Rh atoms confined in the framework of ZSM-5, the yield of acetic acid can reach approximately $21,295 \mu \mathrm{mol} \mathrm{g}_{\text {cat }}{ }^{-1}$ with a selectivity of $60 \%$ as shown in Fig. 1c. This value of yield was around 435 times higher than that of stoichiometric ratio of rhodium to methyl group $\left(\sim 49 \mu \mathrm{mol} \mathrm{g}_{\text {cat }}{ }^{-1}\right)$, indicating it was not a stoichiometric process from the state change of $\mathrm{Rh}$ species but clearly a catalytic cycle. Furthermore, the products from the conversion of $\mathrm{CH}_{4}$ depend on the property of the used support. As shown in Fig. 1d, the acidity of the zeolite is helpful to obtain acetic acid while the methanol dominated on the catalyst with support of Na ions exchanged ZSM-5 or with addition of $\mathrm{Cu}^{2+}$. Interestingly, methanol was the exclusive product on $\mathrm{Rh}_{1} / \mathrm{TiO}_{2}$ single atom catalysts, which lacked the acidity of H-ZSM-5. Another synchronous work also found that the reaction of methane to methanol was facile on $\mathrm{Rh}_{1} / \mathrm{ZrO}_{2}$ [11]. Thus through modulating the acidity of the support, the desired product of acetic acid or methanol can be tuned. Finally, the probable mechanism is proposed as depicted in Fig. 1e. The functionalized Rh$\mathrm{CH}_{3}$ species on the single atom sites can undergo the oxygen insertion to produce methanol or $\mathrm{CO}$ insertion to produce acetic acid, which was contrast to the well-accepted route of methanol carbonylation.

Undoubtedly, this work gives a sound example to illuminate supported metal catalysts for the activation and functionalization of methane which can not only maximize the atomic efficiency of metal species but also give a desired selectivity of target product. In addition, the results with unprecedented performance will stimulate more efforts to prepare next-generation catalysts and processes for the direct conversion of methane to methanol, acetic acid and other useful chemicals, just as depicted in Editorial summary of Nature. 
Received 18 December 2017; accepted 19 December 2017; published online 22 December 2017

1 U.S. Energy Information Administration (EIA), International Energy Outlook 2014 with Projections to 2040, U.S. Department of Energy 2016

2 Olivos-Suarez AI, Szécsényi À, Hensen EJM, et al. Strategies for the direct catalytic valorization of methane using heterogeneous catalysis: challenges and opportunities. ACS Catal, 2016, 6: 2965-2981

3 Mesters C. A selection of recent advances in C1 chemistry. Annu Rev Chem Biomol Eng, 2016, 7: 223-238

4 Ravi M, Ranocchiari M, van Bokhoven JA. The direct catalytic oxidation of methane to methanol-a critical assessment. Angew Chem Int Ed, 2017, 56: 16464-16483

5 Sushkevich VL, Palagin D, Ranocchiari M, et al. Selective anaerobic oxidation of methane enables direct synthesis of methanol. Science, 2017, 356: 523-527

6 Grundner S, Markovits MAC, Li G, et al. Single-site trinuclear copper oxygen clusters in mordenite for selective conversion of methane to methanol. Nat Commun, 2015, 6: 7546

7 Periana RA, Taube DJ, Gamble S, et al. Platinum catalysts for the high-yield oxidation of methane to a methanol derivative. Science, 1998, 280: 560-564

8 Periana RA, Mironov O, Taube D, et al. Catalytic, oxidative condensation of $\mathrm{CH}_{4}$ to $\mathrm{CH}_{3} \mathrm{COOH}$ in one step via $\mathrm{CH}$ activation. Science, 2003, 301: 814-818

9 Kokalj A, Bonini N, Sbraccia C, et al. Engineering the reactivity of metal catalysts: a model study of methane dehydrogenation on Rh (111). J Am Chem Soc, 2004, 126: 16732-16733

10 Shan J, Li M, Allard LF, et al. Mild oxidation of methane to methanol or acetic acid on supported isolated rhodium catalysts. Nature, 2017, 551: 605-608

11 Kwon Y, Kim TY, Kwon G, et al. Selective activation of methane on single-atom catalyst of rhodium dispersed on zirconia for direct conversion. J Am Chem Soc, 2017, 139: 17694-17699 